Paidéia, 2002, 12(22), 103-106

\title{
A PROPÓSITO DAS CONSCIÊNCIAS: DIÁLOGO COM ARNO ENGELMANN'
}

Livia Mathias Simã ${ }^{2}$

RESUMO: Este texto é resultado de um exercício de reflexão, desde a ótica semiótico-construtivista, a respeito de alguns aspectos centrais das formulações teóricas de Arno Engelmannn sobre consciência. - Inicialmente é feita uma síntese das proposições de Engelmann sobre o tema, consideradas centrais para esta reflexão. A seguir, são indicadas, em contrapartida, algumas proposições nucleares do construtivismo semióticocultural, com respeito à relação sujeito-realidade, que podem estabelecer diálogo com as proposições engelmanianas, anteriormente destacadas. Finalmente, são colocadas algumas questões a respeito da abordagem de Engelmann à consciência, advindas desse diálogo.

Palavras-chave: construção do conhecimento; consciência

\section{ABOUT CONSCIOUSNESS: DIALOGUE WITH TO ARNO ENGELMANN}

ABSTRACT: This paper arises from a semiotic-constructivist reflective exercise respect to some central features of Arno Engelmann's theoretical formulations about consciousness. First, some of the main Engelmann's proposals about the focused subject are summarized. Following and in counterpart, some nuclear semiotic-construtivist proposals addressing to the subject-reality relationship, which can be viewed as establishing a dialogue with the previously Engelmaniann formulations, are highlighted. Last but not least, some questions respect to the Engelmann's approach to consciousness followed from that dialogue are set to be discussed.

Key words: construction of knowledge; consciousness.

Estamos inevitavelmente sempre falando de algum lugar. As discussões filosóficas têm talvez como principal ganho nos fazer refletir sobre as implicações ético - científicas de estarmos em determinado lugar. E estaremos sempre em algum.

Estou falando aqui da perspectiva da psicologia construtivista semiótico - cultural, com a qual tenho me envolvido para abordar as relações entre interação verbal e processos de construção de conhecimento, com ênfase nas construções possíveis para o sujeito, diante do significado afetivo - cognitivo que a relação com o outro tem para ele (Simão, 2000a; 2000b; 2001; 2002a; 2002b).

Deste lugar, sempre damos especial atenção ao contexto em que as ações ocorrem, porque elas só podem ser compreendidas êm seu significado

\footnotetext{
' Artigo recebido para publicação em 07/02: aceiro em agosto de 2002.

- Endereço para correspondência: Instituto de Psicologia da Universidade de São Paulo. Av. Prof. Mello Moraes, 1721 - Cidade Universitária A de Salles Oljveira, 05508-9000 São Paulo SP Brasil. E-mail: limsimao (o) usp.br.
}

afetivo - cognitivo quando contextualizadas.

É justamente neste sentido contextual, e não apenas formal e de "boas maneiras", que agradeço ao José Lino pela oportunidade de estar aqui com vocês, na USP Ribeirão Preto, fazendo a tentativa bastante estimulante e difícil de refletir, criticamente e de maneira sintética, sobre algumas das idéias que tiveram grande influência na minha formação acadêmica: as idéias do professor, amigo e colega Arno Engelmann sobre consciência.

"Mas o relato verbal relata o relatado num efeito de inferência" (Engelmann, 1985, p. 2). Felizmente ou infelizmente, não computei quantas horas, com idas e vindas, Beth Tunes ${ }^{3}$ e eu nos debruçamos sobre esta formulação do Arno, quando fazíamos nossas teses de mestrado e doutoramento.... Era, para nós, uma formulação que encerrava o fáscínio e o enigma de nos sentirmos próximas a uma versão filosoficamente relevante dos fenômenos que eram

'Profa. Dra. Elizabeth Tunes (Universidade de Brasília e Universidade Católica de Brasília). 


\section{Livia Mathias Simã}

temas das nossas pesquisas. É bom lembrar que estávamos no final da década de 70, início dos anos 80 do século $\mathrm{XX}$, quando ainda, em alguns setores da Psicologia brasileira, encontrava-se forte resistência ao reconhecimento da condição fascinante e inescapável do ser humano como alguém que se relaciona interpretativa e inferencialmente com sua própria experiência. Aquela formulação do Arno funcionava, pois, emblematicamente como um encorajamento e um aval para nós, já que o pesquisador não foge à regra dos humanos: tem sua ação não só racionalmente, mas também afetiva e emocionalmente orientada. Não é à toa que minha primeira anotação de aula no curso "A Psicologia como parte da filosofia e das ciências", ministrado pelo Arno em 1989, foi a de que "o que interessa não é como o psicólogo se relaciona com o sujeito, animal ou humano, com o paciente, mas sím como ele vê essa relação". Arno nos abriu, e abre a seus novos alunos, a perspectiva do desafio de tratar com aquilo que é fenomenologicamente significativo, fazendo-o já através de seu próprio discurso nos textos que escreve: interage diretamente com o leitor, na primeira pessoa e no tempo presente, falando da experiência de estar aqui e agora, convidando - o para o diálogo filosófico - cientifico que a partir daí se instala. Não faz mistério de suas opções. Consegue compatibilizar fala coloquial com densidade filosófico - científica, "marca registrada" de seus textos.

Curiosamente, ou compreensivelmente, é daquela mesma proposição do Arno que eu parto nova.mente hoje para delinear aiguns aspectos que penso serem fundamentais para a questão da consciência.

"O relato verbal relata o relatado num efeito de inferência" (Engelmann, 1985, p. 2) implica três instâncias interrelacionadas e fundamentais para essa questão: linguagem, subjetividade e consciência, que, por sua vez, remetem, dialogicamente, ao indizível. ao intersubjetivo e ao inconsciente.

Passo a sintetizar minha conıreensão de algumas das proposiçōes do Arno que considero centrais e que estāo presentes em Engelmann (1983; $1985 ; 1988 ; 1989 ; 1997 ; 2001)$.

O recorte da obra foi, evidentemente, forçoso e o critério que utilizei foi o das interseções mais relevantes que vejo das idéias do Arno com a área de pesquisa que desenvolvo, seja no sentido convergen- te, seja no sentido de problematiza-las ambas.

Para mim, o fenômeno fundamental de que Arno parte é o do conhecimento do mundo pelo eu, ou seja, da questão filosófica das condições de conhecimento, inclusive científico. A possibilidade de conhecer tem como premissas o ceticismo probabilista humano e o emergentismo gestáltico da teoria geral de sistemas de von Bertalanffy.

Desse lugar Arno faz proposições especificamente atinentes à questão da consciência.

A partir dos conceitos de dado primário $\mathrm{e}$ secundário e de hipótese de primeira e segunda ordem, ele chega às formulações de dois tipos de consciência. A consciência do outro, chamada inicialmente de consciência - 2 e posteriormente de consciência mediata, é formada de experiências do outro e reconstruida parcialmente na consciência do eu. Ela é mediata porque conhecida através de fenômenos psicológicos expressivos do outro, como por exemplo a fala. É, portanto, construida e será sempre inferida. Além disso, a consciência mediata é temporal, intencional e determinada pelos estados organísmicos e pela experiência. Ela é uma pequena parte de um dos níveis de organização do ser humano e pressupõe uma relação de conhecimento probabilistica do mundo real pelo eu. Se se postula uma consciência - 2 , haverá, é claro, uma consciência - 1. Ela é a consciência do eu que é dada imediatamente. É atemporal e epistemológica, base de qualquer descoberta do ser humano. A consciência imediata é "maior" que as formas de expressão, por exemplo, a linguagem. Salvo a própria consciência imediata, tudo mais no universo é mediato.

O desdobramento teórico - epistemológico da distinção entre consciências implicou a construçã̃c atual de Arno sobre os dois mundos: o meu - mundo e o resto - do - mundo. O meu mundo advém da consciência imediata e o resto - do - mundo da consciência mediata. Todos nós apresentamos meu mundo e resto - do - mundo, e eles serão sempre diferentes para cada um de nós e para nós mesmos em diferentes momentos de nossas vidas. Nossas proposições sobre o meu - mundo dos outros e o meu - mundo de mim em tempos passados, inclusive imediatamente passados, isto é, sobre o resto - do - mundo para mim, serão sempre inferências 
feitas através de expressões minhas ou do outro. $\mathrm{O}$ mesmo vale para o outro, a respeito de mim. Mas a inferência é um processo singular, individual, donde a construção, o conhecimento inferencial do chamado "mundo", que aqui se define como resto - do - mundo, depende do meu - mundo de cada pessoa.

Passo agora a pontuar rapidamente algumas das proposições centrais do construtivismo semiótico - cultural que podem ter certa convergência com as proposições do Arno que destaquei acima, mas que, ao mesmo tempo, suscitam questões com relação a elas. Na perspectiva dos construtivismos, a realidade é construida e reconstruída pelo eu, através, fundamentalmente, da mediação de formas de expressão do outro que são interpretadas pelo $e u$. Esta interpretação é sujeita à negociação eu outro, especialmente através da interação verbal, dando lugar, muitas vezes, à emergência de novos significados, que serão balizadores (Valsiner, 1997a, 1998) de futuras interpretações e negociações. As formas de expressão e de interpretação variam com a cultura, a época e, principalmente, na mesma pessoa em tempos diferentes, devido à relação dialógica eu - mundo ${ }^{4}$. Neste sentido, sujeito e cultura são mutuamente constitutivos, mas o sujeito é seletivo em sua disponibilidade para a relação eu - outro, que concretiza indiretamente a relação sujeito - cultura.

Dentre as formas de expressão do outro, a expressão verbal tem sido culturalmente privilegiada, daí a centralidade da relação eu - interlocutor na construção da realidade. Neste sentido, sinteticamente falando, o conhecimento da realidade, incluídos aí o si mesmo, o outro e a relação si mesmo - outro, é uma construção e reconstrução a partir da experiência individual mediata, singular e subjetiva, donde o caráter de novidade $e$ irrepetibilidade das construções simbólicas da realidade.

Na relação eu - interlocutor, a experiência com a realidade é, na verdade, experiência com a expressão direta ou indireta (marcas) do outro, que é inter-

\footnotetext{
${ }^{4} \mathrm{~A}$ reclação dialógica, tal como a entendo, supōe que eu - mundo compóem uma díade na qual se definem mutuannente. sem entretanto haver uma fusāo que os torne indistinguiveis. lsto pressupõe a separação inclusiva, no sentido de Valsiner (1997b). onde a própria relação entre os elementos é parte do sistema e, portunto. essencial para se compreenda a própria constituição de cada um
}

pretada pelo eu, que se expressará a partir daí para o outro, que se vê como eu, e assim por diante. $\mathrm{Na}$ interação verbal, a fala é a expressão por excelência interpretada na construção não só do conhecimento sobre a realidade, que é conteúdo da conversa (tematizada na conversa), mas também na construção do outro e da relação eu - outro como realidade.

Dado esse caráter mediado e construtivo da relação eu - mundo, que inclui a relação eu - outro, a realidade é uma versão mais ou menos plausível que o sujeito constrói e reconstrói em seu processo de desenvolvimento, que dura toda sua vida. Este processo construtivo é um processo mental, que se dá num tempo irreversível (no sentido de Prigogine e Valsiner), pela ação simbólica do eu, ação esta que é tanto instrumental - racional como afetivo - subjetiva (Boesch, 1991).

Feita esta rápida síntese gostaria de propor algumas questões, no sentido de provocar diálogo, a partir do enfoque e das preocupações construtivistas que podem ser denotadas pelas palavras - chave emergência do novo, irrepetibilidade, constituição mútua entre sujeito e experiência contextuál, intersubjetividade, alteridade:

1. Penso que as formulações de Arno sobre a consciência se fundamentam e, ao mesmo tempo, enfatizam a precedência do sujeito na construção do resto - do - mundo, que é o mundo possivel de ser compartilhado. Qual seria o papel do outro, da alteridade, nessa construção?

2. Como se coloca, mais exatamente, a relação entre a singularidade dos restos - do - mundo individuais, por um lado, e a repetibilidade como critério científico (Engelmann, 2001, p. 212), por outro? Ou, dito de forma mais ampla, quais as relações da experiência individual, da cultura e da ciência, enquanto restos - do - mundo, com o meu - mundo? As hipóteses básicas não são também pertencentes aos restos - do - mundo individuais?

3. Que relações meu - mundo / resto - do - mundo dariam conta da emergência da novidade nos processos de desenvolvimento ontogenético e cultural?

4. Como a consciência imediata dura apenas um momento, todas as outras consciências do sujeito tornam-se mediatas, como as das outras pes- 
soas (Engelmann, 1997, p. 28). Assim, o eu é sempre mediato como instância para si mesmo e, portanto, jamais capta a si como idêntico. Isto daria conta da experiência de mutabilidade do eu para si mesmo. Mas como ficaria a experiência complementar e essencial de percepção de constância em si mesmo? O mesmo valeria para a experiência com o outro.

5. "Uma consciência não pode conhecer outra consciência do mesmo modo que se conhece a si mesma" (Engelmann, 1997, p. 30). Mas o autoconhecimento não seria igualmente mediato, já que as consciências imediatas são momentâneas, e passam a ser daí lembranças?

\section{Referências Bibliográficas}

Boesch, E.E. (1991). Symbolic Action Theory and Cultural Psychology. Berlin: Springer - Verlag.

Engelmann, A. (1983). O Significado como parte do diálogo. Ciência e Cultura, 35(10), 1452-1455.

Engelmann, A. (1985). Comportamento verbal e relato verbal. Psicologia, 11(1), 1-6.

Engelmann, A. (1988). Duas estruturas de consciência: teoria probabilística e teoria geral de sistemas. Ciência e Cultura, 40 (4), 347 - 354.

Engelmann, A. (1989). Relato verbal, principal representante da consciência - 2 humana. Ciência e Cultura, 41(7).

Engelmann, A. (1997). Dois tipos de consciência: a busca da autenticiddade. Psicologia USP, 8(2), $25-67$.

Engelmann, A. (2001). O meu - mundo e o resto - do - mundo. Psicologia: Refiexão e Crítica, 14(1): 211-223.

Simão, L.M. (2000a). Desequilíbrio e co - regulação em situações de ensino - aprendizagem: análise segundo o conceito de ação comunicativa (Habermas). Psicologia: Reflexão e Crítica, 13(1), 33-38.

Simão, L.M. (2000 b). The role of the other in the process of knowledge construction: Developments from the Symbolic Action Theory of Ernst Boesch. Anais da 3rd. Conference for Sociocultural Research, Campinas, São Paulo, Brasil, CD-ROM e www.fae.unicamp.br/ br2000.

Simão, L.M. (2001). Boesch`s Symbolic Action Theory in Interaction. Culture \& Psychology, 7(4): 485-493.

Simão, L.M. (2002ą). A noção de objeto e a concepção de sujeito em Boesch. Em: L. M. Simão, M. T. C. C. de Souza e N. E. Coelho Júnior. Noção de Objeto, Concepção de Sujeito: Freud, Piaget e Boesch. São Paulo: Casa do Psicólogo.

Simão, L.M. (2002b). O significado da interação verbal para os processos de construção de conhecimento: proposta a partir da ótica boeschiana. Em: S. A. S. Leite (Org.) Cultura, Cognição e Afetividade: a sociedade em movimento. São Paulo: Casa do Psicólogo.

Valsiner, J. (1997a). Culture and the development of children's action - A theory of human development. New York: John Wiley \& Sons, Inc.

Valsiner, J. (1997b). Dialogical models of psychological processes: capturing dynamics of development. Polish Quarterly. of Developmental Psychological, 3(2), 155-160.

Valsiner, J. (1998). The guided mind - A sociogenetic approach to personality. Cambridge: Harvard University Press. 